\title{
Análise vocal (auditiva e acústica) nas disartrias***
}

\author{
Vocal analysis (auditory - perceptual and acoustic) in dysarthrias
}

*Fonoaudióloga. Especialização em Voz pelo Centro de Estudos da Voz (CEV). Pesquisadora Voluntária do Departamento de Fonoaudiologia da Universidade Federal de São Paulo. Endereço para correspondência: Rua Botucatu, 802 - Vila Clementino - São Paulo - SP - CEP 04023-062 (lucianecarrillo@hotmail.com).

**Fonoaudióloga. Professor Doutor Adjunto do Departamento de Fonoaudiologia da Universidade Federal de São Paulo.

***Pesquisa Realizada na Universidade Federal de São Paulo Escola Paulista de Medicina

Artigo Original de Pesquisa

Artigo Submetido a Avaliação por Pares

Conflito de Interesse: não

Recebido em 23.06.2006.

Revisado em 12.09.2006; 27.09.2006; 22.06.2007; 14.08.2007; 20.09.2007; 06.11.2007.

Aceito para Publicação em 06.11.2007.

\begin{abstract}
Background: neurological dysphonias are normally associated to dysarthrias and play an important role when determining the correct diagnosis. The acoustic analysis of the voice is important for understanding the speech motor disorders present in dysarthric patients. Aim: to describe the acoustic and auditoryperceptual characteristics of the voice of the different types of dysarthria. Method: 42 patients with well defined neurological diagnosis of dysarthria, 21 male and 21 female, were evaluated according to auditoryperceptual parameters and acoustic measures. All patients had their voices recorded. Auditory-perceptual voice analysis included: type of voice, resonance (balanced, hypernasal or laryngeal-pharyngeal), loudness (adequate, reduced, increased), pitch (adequate, low, high), and voice onset (isochronic, abrupt or breathy). For the acoustic analysis the following programs were used: GRAM 5.1.7. for the analysis of vocal quality and spectrographic tracing; and Vox Metria to obtain the objective measures. Results: data obtained in the auditory-perceptual analysis indicate that the most present vocal quality was the harsh and breathy voice, laryngeal-pharyngeal resonance and instability on vocal onset. In the acoustic analysis the following was observed: instability in the spectrogram, absence of the upper sub harmonics, presence of noise between the harmonics and reduced maximum phonatory time. Jitter, Shimmer and Glottal to Noise Excitation Ratio were altered in all dysarthrias. Conclusion: the acoustic analysis, associated to the auditoryperceptual assessments, is of assistance in the clinical diagnosis of dysarthrias.
\end{abstract}

Key Words: Dysarthria; Voice Disorders; Speech Acoustics.

\section{Resumo}

Tema: as disfonias neurológicas são comuns nas disartrias e desempenham um importante papel no diagnóstico diferencial. A análise acústica da voz é importante para o entendimento dos distúrbios motores presentes nas disartrias. Objetivo: descrever auditiva e acusticamente a voz nos diferentes tipos de disartria. Método: 42 pacientes disártricos, 21 do sexo masculino e 21 do sexo feminino foram submetidos à análise perceptual-auditiva e acústica. Todos os pacientes foram submetidos à gravação da voz, tendo sido avaliados, na análise auditiva, tipo de voz, ressonância (equilibrada, hipernasal ou laringofaríngea), loudness (adequado, diminuído ou aumentado), pitch (adequado, grave, agudo) ataque vocal (isocrônico, brusco ou soproso), e estabilidade (estável ou instável). Para a análise acústica foram utilizados os programas GRAM 5.1.7 para a análise da qualidade vocal e comportamento dos harmônicos na espectrografia e o Programa Vox Metria, para a obtenção das medidas objetivas. Resultados: na análise auditiva os dados indicam que a voz rouca e soprosa foi a qualidade vocal mais presente, ressonância laringo-faríngea e instabilidade na emissão. Na acústica: traçado espectrográfico instável, ausência dos harmônicos superiores e presença de ruído entre os harmônicos e tempos máximos de fonação diminuídos. As medidas de Jitter, Shimmer e Glottal to Noise Excitation Ratio foram alteradas em todas disartrias. Conclusão: a análise acústica, complementar à perceptual-auditiva, auxilia no diagnóstico clínico das disartrias.

Palavras-Chave: Disartria; Distúrbios da Voz; Acústica da Fala.

Referenciar este material como:

13 Carrillo L, Ortiz KZ. Vocal analysis (auditory - perceptual and acoustic) in dysarthrias (original title: Análise vocal (auditiva e acústica) nas disartrias). Pró-Fono Revista de Atualização Científica. 2007 out-dez;19(4):381-6. 


\section{Introduction}

Dysarthria is the collective name for speech disorders which result from disturbances in the speech control mechanism due to damage to the central or peripheral nervous systems1.

Neurologic dysphonias are common in dysarthrias and play an important role in differential diagnosis. In cases where laryngeal function is affected by neurologic disturbance, other speech components also tend to be compromised.1

Vocal analysis in patients with neurologic disease can make an important contribution towards reaching a differential and early diagnosis as well as in following up disease progression2.

In recent years, acoustic and physiological analyses have been applied in patients with neurologic diseases3. Acoustic analysis, always complementary to auditory assessment, aids quantification of data and description of correlations of perceptive judgments on speech intelligibility, voice quality and dysarthria type.

The main objectives of acoustic analysis include: to contribute toward the diagnosis of neurologic diseases of different neurologic subsystems, to document progressive degeneration of neurologic disease, as well as to identify subclinical manifestations of neurologic disease ${ }^{4,5,6}$.

The aim of the current study was to clinically and objectively describe voice in different types of dysarthrias. To this end, more specific objectives were devised as follows:

. to perform and describe auditory-perceptive analysis of voice (subjective) in different types of dysarthria.

- to perform and describe acoustic analysis (objective) in the dysarthrias.

\section{Methods}

The present project was approved by the Research Ethics Committee of the Federal University of São Paulo under protocol number 517/ 04. All participants signed a free and informed consent term.

The sample comprised 42 dysarthric patients drawn from the waiting list for treatment at the Acquired Speech and Language Disorders Outpatient Clinic of the Speech Therapy Department of UNIFESP. All patients had defined etiological neurological confirmed diagnoses, and were aged between 16 and 80 years. The sample consisted of both male $(n=21)$ and female $(n=21)$ patients. The sample was characterized according to the Griffiths and Bough7 classification which defines neurologic disease according to anatomic level affected. The distribution of upper neuron disorders in our sample was $6(14.3 \%)$ patients with spastic dysarthria, 1 (2.3\%) with mixed dysarthria (ALS), and 5 (11.9\%) with unilateral upper motor neuron dysarthria (UUMN), whereas for lower neuron disorders there were $8(19 \%)$ patients with flaccid dysarthria. Regarding extrapyramidal system disorders, there were $14(33.3 \%)$ patients with Parkinson disease, 7 (16.7\%) patients with slow hyperkinetic dysarthria (dystonia) and 1 with mixed dysarthria (gravis). Patients with mixed dysarthria accounted for $4.8 \%$ of the sample. There were no patients in our sample with cerebellum disorders. It was evident that patient groups were not homogenous, but representative of the normal referrals made by different sectors of neurology of the UNIFESP-EPM for speech therapy treatment.

All patient voices were recorded directly onto a computer since this represented the best method of recording voice for carrying out subsequent acoustic analysis. Recordings were made using a Plantronix - Model A-20 microphone within a silent environment at a mouth to microphone distance of $10 \mathrm{~cm}$ during held utterance of the /é/ vowel under normal conditions, along with number counting ( 1 to 10), repetition of the phrase "Um homem e uma mulher viram um anjo" (A man and a woman become an angel), a statement on own voice and singing of the "parabéns a você" (Happy Birthday to you) song.

Auditory and acoustic analyses were performed.

The perceptive-auditory assessment entailed analysis of the held vowel and number counting tasks. Following data collection, all patient voice recordings were mixed to undergo auditory analysis, numbering 42 voices, where $10 \%$ of the sample was presented to the assessor for a second time to ensure data reliability.

The following auditory parameters were analyzed: voice type, resonance (balanced, hypernasal or laryngeal-pharyngeal), loudness (adequate, reduced or increased), pitch (adequate, bass, treble), vocal attack (isochronic, harsh, breathy) and vocal stability (stable or unstable).

The GRAM 5.1.7 Programs were used for acoustic analysis providing assessments of vocal quality and harmonics behavior on the spectrograph, while the Vox Metria program from CTS Informática was employed to obtain objective measurements. These two programs enabled calculation of both quantitative and qualitative 
measurements chiefly by means of perceptive hypotheses and observations8,9,10.

Acoustic analysis assessed the /é/ vowel.

Qualitative acoustic analysis/assessment of harmonics behavior included: Spectrographic trace (stable or unstable), subharmonics (present or absent), upper harmonics (present or absent), noise among harmonics (present or absent), definition of harmonics (defined or poorly defined) and emission initiation (adequate, without sonority, or with spikes).

Qualitative acoustic analysis assessed the following parameters: F0 (fundamental frequency) and their disturbance rates (jitter and shimmer), yielding data on similarity of successive glottic cycles and on glottic source stability.

F0 corresponds to the number of vibratory cycles in vocal cords per second, while Jitter indicates short-term variability of fundamental frequency, shimmer indicates short-term variability in amplitude of the sound wave and is a phonatory stability measure, together with noise measurements: GNE- Glottal to Noise Excitation ratio which is an acoustic measure for calculating noise in a series of pulses produced by the oscillation of the vocal cords. This parameter is based on the hypothesis that pulses resulting from collision of the vocal cords generate a synchronous excitation of different frequency bands. However, noise produced by long vocal cords generates noncorrelated excitations. A value approaching one indicates a pulse type excitation (e.g. normal excitation of the glottis) while values closer to 0 result from a noise-type excitation (e.g.: whispered voice). A phonatory deviation diagram is a graph depicting voice behavior, where position on the horizontal axis indicates jitter and shimmer measurements, whilst position on the vertical axis shows noise quantity measurements - GNE. Possible variations for this parameter include a normal phonatory deviation diagram, those altered in the horizontal plane, altered in the vertical plane or altered in both horizontal and vertical planes.

A Radio Shack Chronometer was used to determine maximum phonation time (MPT). The MPT was ascertained for the /é/ vowel.

The data underwent statistical analysis using the following tests: Chi-squared test (X2)(without Yates correction), or Fischer's exact test to compare categorical data, the Student t test for differences amongst mean continuous data and the Mann Whitney (U) was used to compare non-parametric continuous data between the two samples. All analyses were calculated by the SPSS (Package for the Social Sciences) statistics package version 11.5.1 for Windows. A probability (p) of less than 0.05 was establishes to indicate statistical significance.

\section{Results}

Results are shown in the following tables:

Table 1. Most frequent vocal parameters by dysarthria type, based on auditory analysis.

Table 2. Qualitative acoustic analysis (spectrographic trace) for different dysarthria types.

Table 3. Quantitative acoustic analysis (objective data) - relative means for parameters: fundamental frequency, jitter, shimmer, MPT, GNE and phonatory deviation in different dysarthria types.

TABLE 1 . Most frequent vocal parameters by dysarthria type, based on auditory analysis.

\begin{tabular}{|c|c|c|c|c|c|c|}
\hline Dysarthriatype & Voice Type & Pitch & Loudness & Ressonance & Stability & VocalAttack \\
\hline Flaccid & harsh/breathiness & $\begin{array}{l}\text { H: bass } \\
\text { M: tone }\end{array}$ & reduced & lar/phar & unstable & isochronic \\
\hline Spastic & harsh/breathiness/strained & Bass & reduced & Hypernasal & unstable & isochronic \\
\hline Hypokinetic & Breathiness & adequate & adequate & lar/phar & unstable & isochronic \\
\hline Hyperkinetic & Strained-strangled & $\begin{array}{l}\mathrm{H} \text { : bass/tone } \\
\mathrm{M} \text { : adequate }\end{array}$ & adequate & lar/phar & unstable & isochronic \\
\hline UUMN & harsh/breathiness & $\mathrm{H}$ : adequate & reduced & lar/phar & unstable & breathiness \\
\hline Mixed & $\begin{array}{l}\text { Breathiness } \\
\text { (ALS)/strained-strangled } \\
\text { (multiple sclerosis) }\end{array}$ & M:adeq/bass & Adequate/reduced & $\begin{array}{l}\text { lar/phar } \\
\text { Hypernasal }\end{array}$ & unstable & isochronic \\
\hline
\end{tabular}

Legend: UUMN - Unilateral Upper Motor Neuron 
TABLE 2. Qualitative acoustic analysis (spectrographic trace) for different dysarthria types.

\begin{tabular}{lccc}
\hline Dysarthriatype & TraceStability & $\begin{array}{c}\text { Subharmonics } \\
\text { (presence) }\end{array}$ & $\begin{array}{c}\text { Upper Harmonics } \\
\text { (absence) }\end{array}$ \\
\hline Flaccid & unstable & $12 \%$ & $\begin{array}{c}\text { Presence of } \\
\text { noise among } \\
\text { harmonics }\end{array}$ \\
Spastic & unstable & $33 \%$ & $75 \%$ \\
Hypokinetic & unstable & $14 \%$ & $100 \%$ \\
Hyperkinetic & unstable & $14 \%$ & $50 \%$ \\
UUMN & unstable & $20 \%$ & $85 \%$ \\
Mixed & unstable & $50 \%$ & $80 \%$ \\
\hline
\end{tabular}

Legend: UUMN - Unilateral Upper Motor Neuron

TABLE 3. Quantitative acoustic analysis (objective data) - relative means for parameters: fundamental

frequency, Jitter, Shimmer, MPT, GNE and phonatory deviation in different dysarthria types.

\begin{tabular}{|c|c|c|c|c|c|c|}
\hline Dysarthria type & $\mathrm{F}_{0}(\mathrm{~Hz})^{*}$ & $\begin{array}{l}\text { Jitter } \\
(\%)\end{array}$ & $\begin{array}{c}\text { Shimmer } \\
(\%)\end{array}$ & $\begin{array}{c}\text { MPT } \\
\text { (seconds } \\
\text { )** }\end{array}$ & $\begin{array}{c}\mathrm{G} \\
\mathrm{NE}\end{array}$ & $\begin{array}{l}\text { Phonatory } \\
\text { Deviation }\end{array}$ \\
\hline Flaccid & $\begin{array}{l}\text { H: } 139.17 \\
\text { M: } 206.10\end{array}$ & 0.74 & 7.63 & $\begin{array}{l}\text { H: } 8 \\
\text { M: } 6\end{array}$ & $\begin{array}{c}0.7 \\
5\end{array}$ & $50 \%$ normal \\
\hline Spastic & $\begin{array}{l}\text { H: } 153.79 \\
\text { M: } 199.74\end{array}$ & 0.73 & 7.85 & $\begin{array}{l}\text { H: } 9 \\
\text { M: } 8\end{array}$ & $\begin{array}{l}0.6 \\
2\end{array}$ & $50 \%$ normal \\
\hline Hypokinetic & $\begin{array}{l}\text { H: } 138.39 \\
\text { M: } 209.03\end{array}$ & 0.52 & 6.21 & $\begin{array}{l}\text { H: } 9 \\
\text { M: } 8\end{array}$ & $\begin{array}{c}0.6 \\
7\end{array}$ & $64 \%$ normal \\
\hline Hyperkinetic & $\begin{array}{l}\text { H: } 213.06 \\
\text { M: } 206.10\end{array}$ & 1.39 & 11.51 & $\begin{array}{l}\text { H: } 7 \\
\text { M: } 9\end{array}$ & $\begin{array}{c}0.6 \\
4\end{array}$ & $43 \%$ horizontal \\
\hline UUMN & $\begin{array}{l}\text { H: } 165.48 \\
\text { M: - }\end{array}$ & 0.17 & 7.44 & $\begin{array}{l}\text { H: } 9 \\
\text { M: - }\end{array}$ & $\begin{array}{c}0.6 \\
2\end{array}$ & $60 \%$ normal \\
\hline Mixed & $\begin{array}{c}\text { H: - } \\
\text { M: } 195.57\end{array}$ & 0.23 & 5.55 & $\begin{array}{l}\text { H: - } \\
\text { M: } 4\end{array}$ & $\begin{array}{c}0.5 \\
9\end{array}$ & $50 \%$ normal \\
\hline
\end{tabular}

Legend: UUMN - Unilateral Upper Motor Neuron

* No statistically significant differences were observed among mean f0s in different genders for the dysarthria types: flaccid $-\mathrm{p}=0.033$; spastic $-\mathrm{p}=0.161$; hypokinetic $-\mathrm{p}=0.016$; hyperkinetic $-\mathrm{p}=0.692$.

\section{Discussion}

Computerized acoustic analysis provided the basis for investigation in the present study.

Majority of our sample presented hypokinetic dysarthria (33.3\%). An estimated $89 \%$ of patients with Parkinson's Disease experience vocal alterations as the disease progresses 11. Participants in the current study were on a waiting list and already presented onset of voice and speech alterations. Dysarthria in Parkinson's Disease can be characterized by monotonous pitch and loudness, reduced word stress, imprecise consonants and harshness and breathiness in the voice 12. In Brazil, a group of patients with Parkinson's Disease underwent voice assessment, pre and post surgery, using acoustic analysis 13 .

Table 1 shows the results of auditory analysis. With regard to the perceptual characteristics of the voice for different types of dysarthria, our findings closely mirror those reported in the literature14,15.

Reduced loudness is a possible finding in hypokinetic dysarthria16. However, in the current study the most frequent loudness rating found in 
this type of dysarthria was "adequate". Moreover, the most frequent voice type observed in the dysarthrias was harshness or breathiness in the voice, and frequently combined harshnessbreathiness. Concerning the auditory analysis, instability in utterances was seen in the voices of dysarthric patients. This was evidenced by unstable spectrographic trace (acoustic), most probably stemming from weakness, slowness or lack of coordination of laryngeal musculature, notable from the voice, present in neurological dysphonias.

The most common resonance types identified in the dysarthrias were hypernasal, in the case of spastic and mixed dysarthrias, and laryngealpharyngeal in the other types of dysarthria. Patients with neurological problems presented difficulties in balance and resonance, for instance due to poor velar function. Indeed, hypernasality is perceptually evident in some speaking hypokinetics 17, whilst hypernasal resonance is more prevalent in other groups of dysarthric patients. 18

In relation to qualitative measures on acoustic analysis presented in Table 2, the spectrographic trace appeared stable across all dysarthria types, the majority demonstrating a low presence of subharmonics, these being more prevalent in hyperkinetic dysarthria (33\%). Subharmonics correspond to small peaks between consecutive harmonics on the spectrogram. It is known that a harsh voice can be characterized not only by altered jitter and shimmer but also by the presence of subharmonics on the spectrogram19. In addition, the presence of hoarseness and breathiness enhance the presence of noise on the spectrogram.

Concerning the quantitative acoustic variables presented in Table 3, the maximum phonation time was reduced in all dysarthrias. No statistically significant differences were observed among mean maximum phonation times in different genders for the dysarthria types. In relation to quantitative measurements, there was no statistically significant difference in fundamental frequency between genders for different dysarthrias. It is known that acoustic analysis of pitch and loudness illustrates aspects of voice alteration which are hardly detectable by the human ear20. The current study observed that the acoustic correlate of pitch, namely the means of fundamental frequency, proved similar between genders for the different dysarthria types. However, great disparity was observed in minimum and maximum F0, perhaps due to the highly heterogeneous group, and diverse vocal characteristics in relation to the different degrees and types of dysarthria.

Regarding the cycle-to-cycle variables such as jitter and shimmer, we noted these were increased in all types of dysarthria4,5. These measurements are known to be elevated in neurological dysphonias, since they reflect the regularity of vocal cord vibrations, possibly as a result of reduced neuromuscular control over the laryngeal adductor and abductor mechanism. Also, hoarseness can reflect the acoustic jitter measurements, as a result of laryngeal hypotonia asymmetry in turn leading to differences in tension of the vocal cords or vibration of mass, with subsequent irregular oscillation of vocal cords.

Pooling of data from both perceptual auditory and acoustic analyses in the dysarthrias has demonstrated that these two analyses, when conducted in conjunction, can make a valuable contribution to the clinical diagnosis of the dysarthrias.

\section{Conclusion}

Based on auditory and acoustic analyses in the different types of dysarthria, we are able to conclude that acoustic analysis, although complementary to auditory, reveals interesting data on the multiplicity of voice qualities in neurological dysphonias. 


\section{References}

1. Darley F, Aronson AE, Brown Jr. Differential diagnostic patterns of dysarthria. J Speech Hear Res. 1969; 12: 24669.

2. Abberton E. Phonetic considerations in the design of voice assessment material. Logoped phoniatr Vocol. 2005; 30 (4): 175-80.

3. Sun W, Liu H, Wan X, Cong Z, Yang H, Sun Y. The study of phonatory function in myasthenia gravis patients. J. Voice. 2005;30(15):685-7.

4. Amir O, Dukas M, Shnaps-Baum R. The effect of a voice course on the voices of people with and without pathologies: preliminary observations. Logoped Phoniatr Vocol. 2005;30(2):63-71.

5. Deliyski DD, Evans MK, Shaw, HS. Influence of data acquisition environment on accuracy of acoustic voice quality measurements. J. Voice. 2005;19(2):176-86.

6. Urban PP, Rolke R, Wicht S, Keilmann A, Stoeter P, Hopf HC, Dieterich M. Left-hemispheric dominance for articulation: a prospective study on acute ischaemic dysarthria at different localizations. Brain. 2006;129(3):767-77.

7. Griffiths C, Bough D. Neurologic Diseases and their on voice. J. Voice. 2005;3(2):148-56.

8. Eadie TL, Doyle PC. Classification of dysphonic voice: acoustic and auditory-perceptual measures. J. Voice. 2005;19(1):11-4.

9. Putzer M, Wokurek W. Multiparametric description of voice quality for normal male and female voices base don acoustic analyses. Laryngorhinootologie. 2006;85(2):105-12.

10. Awan SN, Roy N. Acoustic prediction of voice type in women with functional dysphonia, J. Voice. $2005 ; 19(2): 268-82$
11. Azevedo RR, Cardoso F, Reis C. Análise acústica da prosódia em mulheres com doença de Parkinson. Arq Neuropsoquiatr. 2003;61(4):999-1003.

12. Pinto S, Ozsancak C, Tripoliti E, Thobois S, Limousin-Dowsey P, Auzou P. Treatments for dysarthria in Parkinson's disease. Lancet Neurol. 2004;3(9):547-56.

13. Mourão LF, Aguiar PM, Ferraz FA, Behlau, MS, Ferraz HB. Acoustic voice assessment in Parkinson's disease patients submitted to posteroventral pallidotomy. Arq Neuropsiquiatr. 2005;63(1):20-5.

14. Medeiros ME. Disatrofonia: uma visão fonoaudiológica. Fonoaudiologia Brasil, 1999;2:27-37.

15. Kent RD, Kim YJ. Toward an acoustic typology of motor speech disorders. Clin Linguist Phon. $2003 ; 17(6): 427-45$.

16. Dromey C. Spectral Measures and Perceptual ratings of hypocinetic dysarthria. J. Med Speech-Lang Pathol. 2003;11:85.

17. Hoodin RB, Gilbert HR. Parkinson dysarthria: an aerodynamic and perceptual description of velopharyngeal closure for speech. Folia Phoniatr, Logop. 1989;41:249.

18. Miranda CS, Soares ECS, Ortiz KZ Eficácia do processo terapêutico fonoaudiológico em grupo para disatria. Fono Atual. 2005;32:32-9.

19. Omori K, Hisayoshi K, Kakani R, Slavit DH, Blaugrund SM. Acoustic characteristics of rough voice subarmonics. J. Voice. 1997;1:40-7.

20. Samuel C, Louis-Dreyfus A, Couillet J, Roubeau B, Bakchine S, Azouvi A. Dysprosody after severe closed head injury: an acoustic analysis. J Neurosurg Psychiatry. 1998;64:482-5. 